\title{
Het digitale jasje van eergerelateerd geweld
}

\author{
(Strafrechtelijke) mogelijkheden en beperkingen ${ }^{*}$
}

\author{
Janine Janssen \& Jeroen ten Voorde
}

\section{Inleiding}

Geweld uit naam van de familie-eer heeft een archaïsche bijklank. Die eercodes, dat is toch gedateerd, daar doen moderne mensen toch niet aan? De politie neemt in de praktijk echter waar dat eerschendingen nog steeds hoog worden opgevat en dat eeropvattingen inmiddels ook in de digitale wereld worden geuit. Kwesties over (dreigend) geweld naar aanleiding van schending en herstel van de familieeer hebben daardoor een ander karakter gekregen. Het is al oud nieuws dat onze sociale relaties almaar meer verweven raken met online contacten. ${ }^{1}$ Dat speelt ook een rol bij gewelddadige eerzaken. Eerder werd daar in PROCES al eens aandacht aan besteed. ${ }^{2}$ In deze bijdrage gaan wij verder hierop in en proberen wij de volgende centrale vraag te beantwoorden: welke mogelijkheden biedt het strafrecht voor opsporing en vervolging van eerzaken met een digitaal jasje? In de eerste paragraaf leggen wij kort uit wat in Nederland wordt verstaan onder eergerelateerd geweld. Vervolgens lichten wij in de tweede paragraaf toe hoe eercodes zich op social media en het internet kunnen manifesteren. Daarna zoomen wij in op de mogelijkheden die het strafrecht biedt om dit soort zaken op te sporen en te vervolgen. In de laatste paragraaf zetten wij de juridische mogelijkheden en beperkingen van het recht nog eens op een rijtje. We sluiten af met een bondig slotakkoord.

\section{Wat is eergerelateerd geweld?}

De vele gezichten van geweld in naam van de familie-eer

Bij conflicten over familie-eer spelen vaak de volgende kwesties een belangrijke rol: het kiezen van een partner, het veroordelen van seksualiteit, verlies van maagdelijkheid en zwangerschappen buiten het huwelijk, en problemen bij het verbreken van relaties. Om de goede naam van de familie te redden en te herstel-

* Prof. dr. Janine Janssen is hoofd onderzoek van het Landelijk Expertise Centrum Eer Gerelateerd Geweld, lector Veiligheid in Afhankelijkheidsrelaties aan Avans Hogeschool, bijzonder hoogleraar Rechtsantropologie aan de Open Universiteit en tevens voorzitter van de redactie van PROCES. Prof. mr. Jeroen ten Voorde is universitair hoofddocent Straf(proces)recht aan de Universiteit Leiden. Hij is tevens als bijzonder hoogleraar strafrechtsfilosofie, leerstoel Leo Polak, verbonden aan de Rijksuniversiteit Groningen en lid van de redactie van PROCES.

1 Zie bijv. J. de Haan, 'Sociale contacten via digitale kanalen', in: Sociaal en Cultureel Planbureau, Sociaal en cultureel rapport 2008, Den Haag: Sociaal en Cultureel Planbureau 2008, p. 365-385.

2 J. Janssen, 'De stekker eruit? Over de relatie tussen cybercrime en geweld in afhankelijkheidsrelaties', PROCES 2015, 5, p. 318-328. 
len kan onder omstandigheden een beroep worden gedaan op (dreigen met) geweld. In het ergste geval kent het geweld een dodelijke afloop, maar onder meer bedreigingen, mishandelingen en ontvoeringen komen ook voor. Daarnaast kunnen betrokkenen te maken krijgen met de 'sociale dood', in die zin dat ze worden buitengesloten en verstoten. ${ }^{3}$

De afgelopen jaren kwamen bij de politie tussen de 1500 en 3000 zaken binnen waarbij rekening gehouden wordt met een geschonden eergevoel als motief voor (dreigend) geweld. Circa 450 tot 500 van die zaken zijn dermate complex dat een beroep wordt gedaan op het Landelijk Expertise Centrum Eer Gerelateerd Geweld (LEC EGG). In 2018 werden er 529 complexe zaken aan het LEC EGG voorgelegd. Het grootste deel van die zaken ging om bedreiging ( $\mathrm{n}=197,37 \%)$ en mishandeling $(n=163,31 \%)$. Ook werden er vijf moorden en doodslagen voorgelegd, alsmede twaalf pogingen daartoe en één geval van zelfdoding. ${ }^{4}$ Hoewel eergerelateerd geweld relatief veel vrouwen raakt, komen ook mannen als (dodelijk) slachtoffer in beeld. ${ }^{5}$ In 2018 waren twee van de vijf fatale slachtoffers mannen. ${ }^{6}$

\section{Eergerelateerd geweld als paraplubegrip}

In de loop der jaren heeft een aantal gedragingen dat met familie-eer in verband kan worden gebracht zoveel extra aandacht gekregen, dat ze in onderzoek en beleid apart worden genoemd als onderdeel van een grotere verzameling gedragingen onder de grote paraplu 'eergerelateerd geweld'. We noemen hier een aantal voorbeelden:

\section{- Besnijdenis van vrouwen en meisjes}

Hierbij gaat het om een ingreep aan de uitwendige vrouwelijke geslachtsorganen die niet strikt medisch noodzakelijk is en wordt uitgevoerd met een beroep op culturele gewoontes. In sommige culturen leeft de gedachte dat een onbesneden vrouw geen geschikte huwelijkskandidaat is. ${ }^{7}$

\section{- Huwelijksdwang, huwelijkse gevangenschap en verborgen vrouwen}

Hierbij gaat het om een religieus of wettelijk huwelijk waarbij de (voorbereidende) huwelijkshandelingen tegen de vrije wil van minstens één van de huwelijkskandidaten heeft plaatsgevonden en waarmee onder een bepaalde vorm van dwang is ingestemd. Van huwelijkse gevangenschap is sprake wanneer een man of vrouw een huwelijk wil beëindigen en daarvoor niet de benodigde medewerking krijgt van de echtgeno(o)t(e). Het gaat hier om een informeel of een religieus huwelijk dat in het land van herkomst van (een van beide) partners rechtsgeldigheid

J. Janssen, Focus op eer. Een verkenning van eerzaken voor politieambtenaren en andere professionals, Den Haag: Boom Criminologie 2017.

4 LEC EGG, Terugblik op 2018. Jaarverslag van het Landelijk Expertise Centrum Eer Gerelateerd Geweld, Den Haag: LEC EGG 2019.

5 Janssen 2017; LEC EGG 2019.

6 LEC EGG 2019.

7 www.pharos.nl. Zie ook R.S.B. Kool, A. Beijer, C.F. Drumpt, J.F., Eelman \& G.G.J. Knoops, Vrouwelijke genitale verminking in juridisch perspectief. Achtergrondstudie, Den Haag: Raad voor de Volksgezondheid en zorg 2005. 
heeft. ${ }^{8}$ Dan is er nog de problematiek van 'verborgen vrouwen', waarbij het gaat om vrouwen die door de partner en/of familie gedwongen worden om in isolement te leven. ${ }^{9}$

\section{- Achterlating en internationale kinderontvoering}

Het komt voor dat vrouwen al dan niet met hun kinderen of de kinderen zelf tegen hun wil en zonder identiteits- en verblijfsdocumenten door hun echtgenoot, vader of beide ouders (in het geval het alleen om kinderen gaat) in het land van herkomst worden achtergelaten. Dit kan samengaan met huwelijksdwang of huwelijkse gevangenschap. ${ }^{10}$ Van internationale kinderontvoering is sprake als een kind ongeoorloofd naar een ander land wordt overgebracht of daar ongeoorloofd wordt vastgehouden door een ouder. Ongeoorloofd wil zeggen in strijd met het gezagsrecht van het land waar het kind zijn gewone verblijfplaats heeft. ${ }^{11}$

\section{Eer in een digitaal jasje}

Een gemene deler: betrokkenheid van jonge mensen

In de inleiding gaven we al aan dat eercodes voor velen antiek aandoen. Social media en internet gelden daarentegen als het toppunt van moderniteit. We gaven verder in het begin aan dat we in deze bijdrage ons willen verdiepen in de relatie tussen beide fenomenen. Dat begint met de constatering dat de beide fenomenen - geweld uit naam van de familie-eer en technologische ontwikkelingen op het gebied van social media en internet - een belangrijke gemene deler hebben: de betrokkenheid van jonge mensen. Laten we het eerst nog eens hebben over de verschijningsvorm van eergerelateerd geweld in de levensloop. In de vorige paragraaf hebben wij er verschillende genoemd, die in Tabel 1 gerangschikt zijn naar de fase in de levensloop waarin zij plaats kunnen vinden.

Tabel 1 laat zien dat veel stenen des aanstoots raken aan minderjarigen en jongvolwassenen. Wanneer we kritisch kijken naar online gedrag, dan zien we dat in die vormen van communicatie jongeren een belangrijke rol spelen. Zo werd in een eerdere bijdrage aan PROCES uitgelegd dat applicaties als WhatsApp en aanver-

8 A. Cornelissens, J. Kuppens \& H. Ferwerda, Huwelijksdwang. Een verbintenis voor het leven? Een verkenning van de aard en aanpak van gedwongen huwelijken in Nederland, Arnhem: Bureau Beke 2009; M. de Koning \& E. Bartels, Over het huwelijk gesproken: partnerkeuze en gedwongen huwelijken onder Marokkaanse, Turkse en Hindostaanse Nederlanders, Den Haag: ACVZ 2005; E. Smits van Waesberghe e.a., Zo zijn we niet getrouwd. Een onderzoek naar omvang en aard van huwelijksdwang, achterlating en huwelijkse gevangenschap, Den Haag: Ministerie van Sociale Zaken en Werkgelegenheid 2014; J. Janssen, Huwelijksdwang. Wat ziet de politie? Een verkenning van casuïstiek uit 2017, Den Bosch: Avans Hogeschool/LEC EGG.

9 L.F. Drost e.a., Leven in gedwongen isolement. Een verkennend onderzoek naar verborgen vrouwen in Amsterdam, Utrecht: Verwey-Jonker Instituut 2012; L. Drost, E. Smits van Waesberghe \& V. Los, Opgesloten in eigen huis. Een onderzoek naar aard en omvang van verborgen vrouwen in Den Haag, Utrecht: Verwey-Jonker Instituut 2015.

10 Kamerstukken II 2014/15, 32175, 53.

11 L. Janssen, Jeugdrecht begrepen, Den Haag: Boom Juridische uitgevers 2013. 
Tabel 1 Issues die aan de familie-eer kunnen raken in de levensloop en mogelijke reacties (bron: Janssen 2017, p. 117)

\begin{tabular}{|c|c|c|}
\hline $\begin{array}{l}\text { Fase in de } \\
\text { levensloop }\end{array}$ & Issues die aan familie-eer raken & Mogelijke reacties \\
\hline $\begin{array}{l}\text { Kindertijd } \\
0-12 \text { jaar }\end{array}$ & $\begin{array}{ll}- & \text { Buiten de echt geboren worden } \\
- & \text { Niet besneden zijn } \\
- & \text { Verzet tegen regels in de familie }\end{array}$ & $\begin{array}{ll}- & \text { Besnijdenis } \\
- & \text { Achterlating } \\
- & \text { (Dreiging met) geweld }\end{array}$ \\
\hline $\begin{array}{l}\text { Puberteit } \\
12-18 \text { jaar }\end{array}$ & $\begin{array}{ll}- & \text { Verzet tegen regels in de familie } \\
- & \text { Niet besneden zijn } \\
- & \text { Verlies maagdelijkheid } \\
- & \text { Buitenechtelijke zwangerschap } \\
- & \text { Verkrachting } \\
- & \text { Het kiezen van een partner }\end{array}$ & $\begin{array}{ll}- & \text { Besnijdenis } \\
- & \text { Gearrangeerd huwelijk } \\
- & \text { Huwelijksdwang } \\
- & \text { Achterlating } \\
- & \text { (Dreiging met) geweld } \\
- & \text { Zelfdoding } \\
- & \text { (Dreiging met) verstoting }\end{array}$ \\
\hline $\begin{array}{l}\text { Jongvolwas- } \\
\text { senheid } \\
\text { I8-24 jaar }\end{array}$ & $\begin{array}{ll}- & \text { Verzet tegen regels in de familie } \\
- & \text { Verlies maagdelijkheid } \\
- & \text { Buitenechtelijke zwangerschap } \\
- & \text { Verkrachting } \\
- & \text { Het kiezen van een partner } \\
- & \text { Echtscheiding en het opnieuw aan- } \\
& \text { gaan van een relatie, eventuele } \\
\text { discussie over voogdij over de kinde- } \\
\text { ren }\end{array}$ & $\begin{array}{ll}- & \text { Gearrangeerd huwelijk } \\
- & \text { Huwelijksdwang } \\
- & \text { Huwelijkse gevangenschap } \\
- & \text { Achterlating } \\
- & \text { (Dreiging met) geweld } \\
- & \text { Zelfdoding } \\
- & \text { (Dreiging met) verstoting }\end{array}$ \\
\hline $\begin{array}{l}\text { Volwassen- } \\
\text { heid } \\
24 \text { jaar en } \\
\text { ouder }\end{array}$ & $\begin{array}{ll}- & \text { Verzet tegen regels in de familie } \\
- & \text { Verlies maagdelijkheid } \\
- & \text { Buitenechtelijke zwangerschap } \\
- & \text { Het kiezen van een partner } \\
- & \text { Verkrachting } \\
- & \text { Gearrangeerde huwelijken } \\
- & \text { Echtscheiding en het opnieuw aan- } \\
& \text { gaan van een relatie, eventuele } \\
\text { discussie over voogdij over de kinde- } \\
\text { ren }\end{array}$ & $\begin{array}{ll}- & \text { Huwelijksdwang } \\
- & \text { Huwelijksgevangenschap } \\
- & \text { Achterlating } \\
- & \text { (Dreiging met) geweld } \\
- & \text { Zelfdoding } \\
- & \text { (Dreiging met) verstoting }\end{array}$ \\
\hline
\end{tabular}

wanten als ware levensaders voor jongeren fungeren, maar dat hun ouders vooral beducht zijn voor de gevaren van online gedrag en communicatie. Er werd zelfs geopperd dat er sprake lijkt van een slachtofferparadox, waarmee bedoeld wordt dat de groep die het meest enthousiast en blijkbaar onbevreesd gebruikmaakt van ICT, in de praktijk helaas wel het grootste risico op slachtofferschap loopt. Jongeren lijken zich niet altijd goed te realiseren hoe gevaarlijk de digitale wereld kan zijn. $^{12}$

Online communicatie over zaken die de familie-eer raken

Hoewel wij niet over het hoofd zien dat social media en internet ook veel positiefs heeft gebracht, ook voor slachtoffers en andere betrokkenen bij eerzaken - denk in dit verband alleen al aan de mogelijkheden om informatie op te zoeken of om waardevolle sociale relaties met familieleden in het buitenland in stand te houden -, willen we hier vooral inzoomen op risico's en gevaren die wij waarnemen. Het 
schenden en herstellen van geschonden familie-eer kent inmiddels namelijk ook een digitale variant. Het wordt dikwijls oneervol gevonden als jonge of al gehuwde mensen online contact leggen met anderen met het oog op het aangaan van een (seksuele) relatie. Hier gelden dezelfde restricties die offline gelden. Daarnaast komt het geregeld voor dat betrokkenen aangeven dat zij vrezen dat schadelijke roddels niet alleen op familiebijeenkomsten of andere sociale gelegenheden worden verbreid, maar dat die ook (lees: juist) via het internet razendsnel zullen worden doorgebriefd. Denk in dit verband bijvoorbeeld aan issues als het verlies van maagdelijkheid of het hebben van een buitenechtelijke relatie. Daarnaast nemen wij waar dat online communicatie ook een belangrijke rol speelt bij het beïnvloeden van ongewenst gedrag van familieleden. Mensen worden niet alleen in het kader van het voorkomen van eerschendingen of eerherstel onder druk gezet of gechanteerd..$^{13}$ Tevens zien we dat mensen onder druk worden gezet om oneervolle activiteiten te beginnen of te continueren. In dit verband kan bijvoorbeeld gedacht worden aan gedwongen werk in de seksindustrie. ${ }^{14}$

\section{Computercriminaliteit en het strafrecht}

\section{Strafbaarheid van online gedragingen}

Online met elkaar communiceren is een grondrecht (vrijheid van meningsuiting) dat niet zomaar mag worden beperkt. Tot die communicatie behoort ook het verspreiden van beeldmateriaal; in een beeldcultuur als de onze wordt allang niet meer slechts met woorden gecommuniceerd. Ook het digitaal verspreiden van beeldmateriaal wordt tot de vrije meningsuiting gerekend en valt onder het daarop betrekking hebbende grondrecht (zie bijvoorbeeld art. 10 lid 1 Europees Verdrag voor de rechten van de mens (EVRM)). ${ }^{15}$

Het recht op vrije meningsuiting is evenwel niet absoluut; het kan worden beperkt (art. 10 lid 2 EVRM). Daarvoor moet weliswaar een 'dringende maatschappelijke noodzaak' bestaan en is het 'choqueren, kwetsen en verontrusten' van anderen toegestaan, dat neemt niet weg dat aan (online) communicatie grenzen kunnen worden gesteld en dat die grenzen door middel van het strafrecht kunnen worden gehandhaafd. Het Europees Hof voor de Rechten van de Mens (EHRM) wijst erop dat schadelijke online communicatie eenvoudig kan worden verspreid en slechts met veel moeite van het internet kan worden verwijderd. Die omstandigheden zijn relevant bij de beoordeling van de begrenzing van de vrijheid van meningsuiting, ${ }^{16}$ bijvoorbeeld door middel van het strafrecht.

13 J. Janssen, R. Sanberg \& D. van der Sluis, 'Virtual honour: violating and restoring family honour through the internet', in: Cahiers Politiestudies 2011, 20, p. 275-293; Janssen 2015; Janssen 2017. Zie https://nos.nl/artikel/2257445-loverboy-3-0-dwingt-nederlandse-meisjes-tot-werk-inbelgisch-bordeel.html (bekeken op 13 maart 2019).

14 J. Janssen \& M. Rasenberg, 'Dangerous liaisons. Over de relatie tussen eergerelateerd geweld en mensenhandel', PROCES 2017, p. 438-447.

15 Zie bijv. EHRM 10 maart 2009, 3002/03 en 23676/03 (Times Newspapers Ltd. (nrs. 1 en 2)/ Verenigd Koninkrijk); EHRM 18 december 2012, 3111/10 (Ahmet Yildirim/Turkije).

Zie o.a. EHRM 16 juni 2015, 64659/09 (Delfi/Estland), par. 110. 
We bespreken hier een aantal strafbaarstellingen en dalen af van tamelijk vanzelfsprekende strafbaarstellingen van online communicatie naar een aantal problematische gevallen. In de volgende deelparagraaf bespreken we nieuwe wetgeving.

Het voeren van gesprekken of het verzenden van beeldmateriaal langs digitale weg kan gepaard gaan met bedreiging of chantage. Denkbaar is bijvoorbeeld dat iemand op de hoogte raakt van een gesprek tussen een jongen en een meisje en een van beiden of hen allebei bedreigt (met geweld). Indien de bedreiging een 'gerechtvaardigde vrees' oplevert, spreken we van bedreiging (art. 285 Wetboek van Strafrecht $(\mathrm{Sr})$ ). Wanneer die bedreiging gepaard gaat met het stellen van eisen, bijvoorbeeld het krijgen van geld (teneinde te voorkomen dat het eerschendende gedrag aan anderen wordt doorverteld), kan worden gesproken van afpersing (art. 317 Sr). Daarnaast kan pikant beeldmateriaal via social media worden verspreid. Denkbaar is dat bijvoorbeeld klasgenoten of collega's op het werk daarmee bekend raken en iemand de persoon die is afgebeeld benadert en ermee dreigt het materiaal aan de ouders of familieleden van de persoon te geven, tenzij die persoon meer beeldmateriaal van zichzelf stuurt. Dergelijk gedrag kan als afdreiging worden gekwalificeerd (art. $318 \mathrm{Sr}$ ). Wanneer het beeldmateriaal seksueel van aard is, spreken we ook wel van seksuele afpersing. Seksuele afpersing, of sextortion, is een fenomeen dat nationaal en internationaal veel aandacht krijgt. Zij kan veel ellende veroorzaken, tot en met de gekozen of gedwongen zelfdoding van het afgeperste slachtoffer. ${ }^{17}$

Pikant beeldmateriaal kan ook worden gehackt. Dat is een vorm van computervredebreuk (art. 138ab Sr). Tijdens een hack kan de camera van de computer of mobiele telefoon worden geactiveerd, waardoor pikant beeldmateriaal wordt gemaakt zonder dat het slachtoffer daarvan op de hoogte is. Ook dat is strafbaar. ${ }^{18}$ Wanneer vervolgens beeldmateriaal wordt gemaakt van een minderjarige (dat wil zeggen een persoon jonger dan 18 jaar), kan dat kinderporno opleveren, mits het materiaal een seksuele gedraging toont (art. 240b Sr). Het verspreiden van dergelijk materiaal (we spreken ook wel van sexting) is eveneens strafbaar op grond van artikel $240 \mathrm{~b}$ Sr. Dat is ten aanzien van meerderjarigen minder vanzelfsprekend. Indien het gaat om heimelijk in een woning gemaakt materiaal, is strafbaarheid waarschijnlijk wel gegeven (zie onder andere art. 139f Sr). Ook het verspreiden van dergelijk materiaal is strafbaar gesteld (art. 139g Sr). Met betrekking tot niet heimelijk gemaakt materiaal ligt dat gecompliceerder. Gelet op het zelfbeschikkingsrecht en de seksuele vrijheid kan het worden beschouwd als de verantwoordelijkheid van de persoon die is afgebeeld of deze seksueel beeldmateriaal van zichzelf maakt en aan een ander verspreidt. Dat die persoon zichzelf daarmee in gevaar brengt, is op dit moment in belangrijke mate voor risico van de betrokkene. Ook wanneer het materiaal vrijwillig aan een ander is gegeven, terwijl die ander zonder toestemming van de afgebeelde persoon het materi-

17 Zie J. Wolak e.a., 'Sextortion of Minors: Characteristics and Dynamics', Journal of Adolescent Health 2018, p. 72-79.

18 Hetzelfde geldt voor de situatie dat met een hack een gps-tracker wordt aangezet waardoor de gangen van een persoon kunnen worden nagegaan. Zie voor dit voorbeeld: Janssen 2017. 
aal verspreidt, is strafbaarheid niet eenvoudig te construeren. In de rechtspraak is wel aangenomen dat daarmee de eer en goede naam van een persoon wordt gekrenkt en er dus sprake is van belediging of smaad (art. 261 e.v. Sr). ${ }^{19}$

Het voeren van gesprekken over seks via social media is niet strafbaar, tenzij die gesprekken met minderjarigen worden gevoerd en een bepaald doel hebben, namelijk het seksueel misbruiken van die minderjarigen. Dergelijk gedrag kan strafbaar zijn: het levert bijvoorbeeld grooming (art. 248e Sr) of poging tot misleiding (art. 45 jo. 248a Sr) op. Het eermotief hoeft hier geen rol te spelen, maar wanneer dergelijke gedragingen worden geconstateerd, kan dat een eerschending opleveren waarbij niet is uitgesloten dat zij ook voor het slachtoffer nadelig kunnen uitpakken. Strafbaarstelling van communicatie over seks lijkt bij eerzaken vooral relevant om te voorkomen dat het tot een eerschending komt, althans dat de eerschending door derden (familie en bekenden) wordt ontdekt.

\section{Nieuwe wetgeving}

Er ligt een wetsvoorstel waarin het verspreiden van seksueel beeldmateriaal met het oogmerk van benadeling (art. 139h Sr) als nieuwe strafbaarstelling wordt geïntroduceerd. ${ }^{20}$ Met dat wetsvoorstel wordt beoogd onder omstandigheden ook meerderjarigen te beschermen die vrijwillig seksueel beeldmateriaal aan een ander hebben gezonden of door een ander hebben laten maken. Het oogmerk van benadeling lijkt wel gegeven bij het openbaar maken van materiaal dat kan leiden tot een eerschending, gelet op alle mogelijke consequenties daarvan.

Op 1 maart 2019 trad de langverwachte Wet Computercriminaliteit III in werking. ${ }^{21}$ De wet voorziet onder andere in de strafbaarstelling van het opzettelijk en wederrechtelijk voor zichzelf of een ander overnemen van niet-openbare gegevens die zijn opgeslagen door middel van een geautomatiseerd werk (zoals een computer of smartphone). Deze strafbaarstelling (art. 138c Sr) is vooral bedoeld om het onrechtmatig overnemen van bedrijfs- of andere gegevens te kunnen bestraffen zonder dat er sprake is van computervredebreuk, ${ }^{22}$ maar de strafbepaling kan ook relevant zijn in het kader van het tegengaan van eergerelateerd geweld. Niet-openbare gegevens kunnen chatgesprekken zijn die een persoon met een andere persoon heeft gevoerd en die - wanneer zij openbaar worden - een eerschending opleveren. Ook fotomateriaal dat niet voor verspreiding is bedoeld en dat wordt bemachtigd, kan in het kader van de aanpak van eergerelateerd geweld relevant zijn. Ter voorkoming van escalatie van het eerconflict kan het van belang zijn dat wordt verhinderd dat het beeldmateriaal wordt verspreid.

19 Kritisch daarover is M. Goudsmit, 'De wijzende vinger bekeken. Over de strafbaarstelling van wraakpornografie', NJB 2018, p. 1722-1723.

20 Kamerstukken II 2018/19, 35080, 2. Zie daarover J.M. ten Voorde, 'Heimelijk of zonder toestemming. Op zoek naar de juiste grondslag van de nieuwe strafbaarstelling van misbruik van seksueel beeldmateriaal', $D D$ 2019, p. 84-97.

21 Wet van 27 juni 2018, Stb. 2018. 322.

22 Kamerstukken II 2015/16, 34372, 3, p. 65, 66, 86-87. 
De Wet Computercriminaliteit III introduceert ook nieuwe opsporingsbevoegdheden in het digitale domein. ${ }^{23}$ Naast het doorzoeken van een plaats ter vastlegging van gegevens die op een computer (of smartphone of tablet) zijn opgeslagen en het bevel toegang te verschaffen tot die gegevens (art. 125i e.v. Wetboek van Strafvordering (Sv)), kan ook vertrouwelijke communicatie worden opgenomen (art. $126 \mathrm{l} \mathrm{Sv}$ ). Tevens kunnen gegevens, zoals chatgesprekken, worden gevorderd (art. 126ng Sv). Nieuwe opsporingsbevoegdheden zijn het hacken in een geautomatiseerd werk door een opsporingsambtenaar (art. 126nba Sv) en het ontoegankelijk maken van gegevens, voor zover noodzakelijk ter beëindiging van een strafbaar feit of ter voorkoming van nieuwe strafbare feiten (art. 125p $\mathrm{Sv}$ ). Met de laatste bevoegdheid kunnen gegevens (zoals strafbaar beeldmateriaal) ontoegankelijk worden gemaakt, waardoor een mogelijke eerschending niet aan het licht komt of escalatie van een eerconflict wordt voorkomen. Uit rechtspraak blijkt dat ook onderzoek aan een smartphone is toegestaan, mits daarbij geen meer dan beperkte inbreuk op de persoonlijke levenssfeer wordt gemaakt. ${ }^{24}$

\section{Knelpunten politie opsporing en handhaving}

\section{Heimelijk}

Het inzetten van deze bevoegdheden geschiedt veelal heimelijk. Dat kan in eerzaken voordelig zijn, omdat juist in die zaken openbaarheid tot problemen kan leiden. Tegelijkertijd hebben deze bevoegdheden hun beperkingen. Eenmaal op het internet is het verwijderen of ontoegankelijk maken van informatie erg lastig. Gegevens die op een bepaalde plaats ontoegankelijk zijn gemaakt, kunnen zijn gekopieerd en vervolgens op een andere plaats weer opduiken. Zo ontstaat het beeld van de dweil en de openstaande kraan.

\section{Internationaal}

We moeten ons ook realiseren dat het internet zich weinig aantrekt van staatsgrenzen en rechtsmacht, terwijl staten met een beroep op soevereiniteit grote waarde hechten aan grenzen en begrenzing van rechtsmacht. Stel echter dat een verbolgen man een Facebookaccount op naam van zijn ex-vrouw aanmaakt en met behulp van naaktfoto's van zijn ex-vrouw doet voorkomen dat zij in ruil voor geld seksuele diensten aanbiedt. Dat bericht kan in Nederland worden gelezen, maar ook door haar familie in een ander land, ver van Nederland. De familieleden die het bericht lezen, kunnen zeer boos worden omdat uit het bericht zou blijken dat de vrouw de familie-eer heeft aangetast. Het is voorgekomen dat met de vrouw contact wordt opgenomen en haar te verstaan wordt gegeven dat zij de foto's van internet verwijdert. Doet ze dat niet, dan zal zij worden gedood. ${ }^{25}$ De vrouw kan de foto's niet verwijderen, nu niet zij, maar haar ex-man de foto's in bezit heeft en de Facebookpagina beheert waarop ze zijn te zien. De feiten die de

23 Zie J.J. Oerlemans, 'De Wet Computercriminaliteit III: meer handhaving op internet', Strafblad 2017, p. 350-359.

24 HR 4 april 2017, NJ 2017/229, m.nt. red.; HR 18 december 2018, NJ 2019/84, m.nt. Kooijmans.

25 Zie Janssen 2017. 
man heeft gepleegd, kunnen wellicht als belediging of smaad worden beschouwd en in de toekomst strafbaar zijn als wraakporno (art. 139h Sr), maar daarmee zijn de foto's nog niet verwijderd. Facebook kan wellicht worden gedwongen de foto's te verwijderen (ex art. 125p Sv), maar wat als Facebook dat weigert, of wat als de provider waarop de foto's ook zijn te vinden zich niet op Nederlands grondgebied bevindt? In dat geval is internationale rechtshulp nodig. Die kan worden ingeschakeld, maar is niet altijd even snel en niet altijd succesvol. Nederland heeft met sommige landen een goede rechtshulprelatie, wat de kans op succes wellicht helpt vergroten. De kans op succes zal verminderen in het geval de rechtshulprelatie met een ander land niet zo goed is. ${ }^{26}$

Voor regels van internationale rechtshulp in het kader van computercriminaliteit binnen de Raad van Europa moet men te rade gaan bij het Cybercrimeverdrag. ${ }^{27}$ Dat verdrag regelt niet alleen de samenwerking tussen verdragsstaten, maar biedt onder omstandigheden ook de mogelijkheid voor staten om zonder toestemming van andere staten de volgende opsporingshandelingen te verrichten: toegang verschaffen tot opgeslagen publieke toegankelijke computergegevens, ongeacht waar deze zich in geografisch opzicht bevinden, of via een computersysteem dat zich in het land bevindt, en 'toegang verschaffen tot of de beschikking krijgen over opgeslagen computergegevens die zich bevinden in een andere Staat, indien de Partij de rechtmatige en vrijwillige instemming verkrijgt van de persoon die gerechtigd is de gegevens via dat computersysteem aan de Partij te verstrekken' (art. 32 Cybercrimeverdrag). ${ }^{28}$

\section{Regels}

Toegang hebben tot bronnen op internet betekent niet dat het onderzoek op internet zonder regels is. Met bronnen op internet wordt gedoeld op bronnen die volledig vrij toegankelijk zijn tot bronnen die slechts via registratie toegankelijk zijn tot bronnen die slechts door betaling toegankelijk zijn. Onderzoek naar niet vrij toegankelijke bronnen is onder voorwaarden mogelijk (vergelijk art. 126m e.v. Sv). Onderzoek naar vrij toegankelijke bronnen zal kunnen worden gebaseerd op artikel 3 Politiewet 2012. Tegelijkertijd wijst Koops erop dat ook vrij toegankelijke bronnen privé-informatie kunnen bevatten die wordt beschermd door het recht op privacy (art. 8 EVRM). Dat recht kan weliswaar worden beperkt (art. 8 lid 2 EVRM), maar dat neemt niet weg dat het systematisch en grootschalig verzamelen van gegevens van een persoon de persoonlijke levenssfeer behoorlijk kan raken, zozeer zelfs dat van een meer dan geringe inbreuk op de privacy kan worden gesproken. In dat geval zou volgens Koops sprake kunnen zijn van stelsel-

Kamerstukken II 2014/15, 34372, 3, p. 8-9, 12.

Binnen de EU zijn van belang Richtlijn 2011/93/EU ter bestrijding van seksueel misbruik en seksuele uitbuiting van kinderen en kinderpornografie, en Richtlijn 2013/40/EU over aanvallen op informatiesystemen.

8 Zie over dit verdrag F. Calderoni, 'The European legal framework on cybercrime: striving for an effective implementation', Crime, Law and Social Change 2010, p. 339-357 en - alweer wat (ver)ouder(d) - B.J. Koops, 'Het Cyber-crimeverdrag, de Nederlandse strafwetgeving en de (computer)criminalisering van de maatschappij', Computerrecht 2003, p. 115-123. 
matige observatie van een persoon. Een dergelijke bevoegdheid is in geval van een verdenking aan eigen wettelijke regels gebonden (art. 126g Sv). ${ }^{29}$

Koops wijst ook op andere wettelijke bevoegdheden, waaronder het stelselmatig inwinnen van informatie (art. 126j Sv). Daarvan is bijvoorbeeld sprake wanneer een opsporingsambtenaar die zich als zodanig niet kenbaar heeft gemaakt, deelneemt aan chatgesprekken en op die manier informatie inwint over een verdachte. ${ }^{30}$ Ook het stelselmatig inwinnen van informatie is aan wettelijke regels gebonden.

\section{Expertise}

Aan digitale opsporing wordt tegenwoordig prioriteit gegeven. De achterstand in kennis en vaardigheden op dit terrein wordt langzaam maar zeker ingehaald. Tegelijkertijd staat de digitale wereld niet stil en worden nieuwe manieren gevonden om op een wijze te communiceren die voor opsporingsinstanties in het verborgene blijft, althans voor hen een nieuwe uitdaging betekent. Blijvend investeren in goed opgeleid personeel en voldoende apparatuur om hoogwaardige digitale opsporing te blijven uitvoeren, is daarom noodzakelijk. Dat geldt niet alleen in het kader van de aanpak van digitale, georganiseerde en ondermijnende criminaliteit, maar ook voor gevallen als eergerelateerd geweld, waar de gevolgen dramatisch kunnen zijn voor de betrokkenen, maar ook voor de samenleving als geheel.

\section{Slot}

Moderne techniek beïnvloedt onze sociale relaties en zelfs ook intieme, seksuele contacten. Dat is een van de redenen waarom er wordt gewerkt aan nieuwe wetgeving op het gebied van zedendelicten. Die wetgeving is ook relevant voor de aanpak van eergerelateerd geweld. In deze bijdrage hebben wij willen laten zien dat ondanks het gegeven dat eercodes bij wijze van spreken al zo oud zijn als de weg naar Rome, zij zich toch goed weten aan te passen aan moderne communicatievormen. We juichen kortom toe dat de wetgever rekening houdt met ontwikkelingen in de samenleving. We zijn daarnaast benieuwd wat een en ander in de praktijk voor de handhaving zal gaan betekenen.

29 B.J. Koops, 'Politieonderzoek in open bronnen op internet. Strafvorderlijke aspecten', Tijdschrift voor Veiligheid 2012, p. 34-37.

30 Koops 2012, p. 38-40. 